Research Strategies, 2000, Vol. 17, No. 2-3, p. 123-132.

ISSN: $0734-3310$

http://www.sciencedirect.com/science/journal/07343310/17/2-3

http://www.sciencedirect.com/science/article/pii/S0734331000000367

http://dx.doi.org/10.1016/S0734-3310(00)00036-7

Copyright (C) 2001 Elsevier Science Inc. All rights reserved

\title{
The learning library in context: community, integration, and influence
}

\author{
Kevin Simons, James Young, Craig Gibson
}

\begin{abstract}
The learning library is a construct based on the sociocultural theories of Lev Vygotsky and Jean Lave. These theories hold that learning happens through social interaction, that learners move through increasingly complex zones of development through the assistance of more capable others, and that real learning is situated only in specific cultural environments. The learning library bases its programs and services on these ideas through programmatic partnerships with specific groups such as learning communities and cohorts of students; through curricular integration so that learning about information resources is situated within the daily life of the college or university; through using the library as a locus for, and facilitator of, sustained interactions among students, faculty, and librarians; and by using the social interactions developed among communities of learners to extend the influence of the library throughout the institution. This article examines how these facets of the learning library are reflected in four programmatic models at George Mason University's Johnson Center Library: the course-integrated model (New Century College, NCC), the course-related model (English 101: Composition), the orientation/peer advising model (University 100: University Life), and the information/term paper counseling and coaching model (partnership with the University's Writing Center, WC). (C) 2001 Elsevier Science Inc. All rights reserved.
\end{abstract}

\section{What is a learning library? Some contextual theory to guide us}

The "learning library" manifests itself in diverse ways on various college and university campuses. The "learning library" concept itself centers on four interwoven strands of communication and interaction among students, faculty, librarians, information resources, and curriculum: active programmatic partnerships; curricular integration; sustained interactions among students, faculty, and librarians; and extension of influence into a "multiplier effect " The central idea of the learning library is that of integration: the library becomes an essential component of students' formal education and informal research needs. Rather than an external "add on" to the educational experience, the library, as information resource and gateway, is a primary catalyst for cognitive, behavioral, and affective changes in students - as they interact with information resources as directed by faculty, as they complete assignments and study with peers, as they extend their knowledge at multiple levels, seeking connections and making meaning in more self-directed ways. The learning library, rather than a repository of materials or a study hall, is therefore an agency of change in students' lives.

The four strands of communication and interaction central to the learning library all depend on social interaction. While there is certainly a place for the solitary scholar in the learning library, newer theories of learning suggest the centrality of collaborative study, of peer mentoring, of conversation as the vehicle for learning. Perhaps Vygotsky's constructivist theories and the pedagogical theories of Jean Lave most clearly undergird the learning library: the idea of novices' "apprenticeship" into more complex and sophisticated thinking processes resulting from continued practice under the guidance of more capable others - whether peers, faculty, or librarians. The 
learning library, following constructivist theory, provides "scaffolding" for the novice learner and information seeker through multiple coaching/mentoring opportunities, whether at the reference desk, in the formal instruction room, in casual conversations in study groups, or in meetings in librarians' offices. "Scaffolding," apprenticeships, and guided learning, in turn, all relate closely to Vygotsky's concept of the zone of proximal development: the idea that learners progress from activities that they can accomplish entirely by themselves as individuals to more complex cognitive tasks only through the guidance and coaching of more capable others - more knowledgeable adults, teachers, and peers (for the fullest exposition of Vygotsky's ideas, see Vygotsky, 1978). This sociocultural concept of Vygotsky has become central to composition theory and other fields and has resulted in such practices as peer mentoring and reciprocal teaching. The learning library itself is a natural manifestation of Vygotsky's ideas: students gain increasing skill with information resources — both in retrieving and evaluating them — through collaborating with peers on research projects, seeing how library staff model information-seeking, asking for assistance and coaching at the reference desk, and using the support system or "scaffolding" provided by human- and computer-mediated assistance to become more adept researchers and information-literate individuals. The learning library provides supports that, in future years, will gradually be removed as students move into workplace environments, internships, and professional positions where they may be called upon to use a wide range of information resources independently and wisely. In the Vygotskian sense, the learning library is the constructivist laboratory for students to make their own meanings, but only by moving through a series of "zones of proximal development" with research strategies and information sources and with the coaching and guidance of more knowledgeable others.

Closely related to Vygotsky's ideas are those of Jean Lave, who is best known for her concepts of "situated cognition" and "communities of practice." Basing her theories on Vygotsky's emphasis on social interaction as the path to higher cognitive skills, Lave believes that students gain expertise, knowledge, and skill, not through individual learning in classrooms in "out-of-context," abstract ways, but through a process of acculturation into communities of expertise located in real situations, not contrived, "academic" ones. For Lave, much learning is tacit rather than intentional: novices become experts through observing how the knowledgeable members of a community act and what is valued in that community. Over time, novice learners move from the "outside" or periphery into the center of the community's activities: the cultural practices of the community begin to make sense as newcomers engage themselves more fully in the community (Lave, 1991). Lave's ideas therefore point to other possibilities for the learning library: student cohort groups that collaborate on research projects; learning communities from specific programs or departments that make the library an essential component of their life, thereby creating "communities of practice" with information resources; and the library as a site for apprenticeship into the complexities of information management - for students, faculty, staff, and an entire campus community. "Situated learning" in the learning library means creating a culture of inquiry and investigation where the ideas of the classroom are tested in the crucible of the contemporary information environment - with all of its redundancy, its conflicting claims, and its mixture of valuable, peer-reviewed resources selected by librarians, Web-based information resources of uncertain quality, and "edutainment." Situating learning in an arena of reasonable complexity and qualified messy reality is one way of applying Lave's ideas to the learning library - the place where students become acculturated into more sophisticated research habits, the locale for incubating "communities of research practice" that connect with real life: internships, service learning, the world of work, public policy investigations, and local environmental and 
political campaigns. Taken together, Vygotsky and Lave's ideas provide all the essential philosophical and educational foundation for the daily practices of the learning library.

With such a foundation in place, certain characteristics of the learning library emerge over time. The first component of the learning library is outreach and programmatic partnerships. The library develops the collaborative skills necessary to "partner" with faculty and administrators in developing information literacy programs and places information literacy and the constructivist "network of associations" at the very heart of the teaching and learning process. Programmatic partnerships lead to curricular integration, so that the library's resources and instruction become essential elements of student success in identified courses and programs. "One-shot" sessions taught by librarians may still have a place, but increasingly the learning library seeks to embed information literacy in the foundations of coursework at a programmatic level so that students have repeated, varied experiences with information seeking. This richer curricular integration leads to, and depends upon, pervasiveness of interactions among students, faculty, and librarians related to information resources and information literacy. Instead of the traditional limited interactions in the instruction room and the reference desk, the learning library leverages those opportunities for further learning in multiple ways: in Web-based instruction to elaborate upon traditional "one shot"; in small group discussions with students and faculty; in peer information counseling and guidance; in office appointments with librarians; and in impromptu, "just-in-time" instruction with students inside or outside the library. All of this interaction, in the learning library, creates a "web of influence" or a multiplier effect in which librarians become more visible on campus, where new instructional opportunities arise, where the teaching and learning environment is transformed because librarians, as change agents, serve on curriculum committees, consult on program planning, work with accreditation study groups, help design new courses, and create a campus environment in collaboration with faculty and administrators where becoming fluent with information resources and skills is essential to students' academic success.

The learning library depicted here may appear idealized, but many academic libraries show some features of the idealized portrait. The range of possibilities for partnerships, curricular integration, pervasive interactions, and the "web of influence" is wide indeed, and few libraries demonstrate the totality of all of these "learning library" elements. The curricular integration and creation of the network of associations central to the learning library both manifest themselves most prominently in the curricular/programmatic models through which the library becomes involved in the teaching and learning process. For librarians, four such models have traditionally been known as course-integrated instruction, course-related instruction, orientation and peer counseling, and information/term paper counseling/guidance. The degree of curricular integration obviously varies across the spectrum of these models; but each model has its place in a total instruction program offered by the learning library, each model may vary in its level of involvement and integration with the academic programs and the life of the campus. In this article, we will examine several manifestations of the learning library at George Mason University.

\section{How does the learning library work at George Mason University? Looking at the theory in practice}

At George Mason University, all four curricular/programmatic models are present in the outreach and instruction programs of the Johnson Center Library: the course-integrated model, with extended, sustained interactions between librarians, students, and faculty, is found most obviously in the New Century College (NCC) program; the course-related model, with the use of a 
customized research guide and the beginnings of a Web tutorial, is related to the English 101 (Basic Composition) program; the orientation/peer advising model is manifested in the outreach program to the University 100 (Introduction to University Life) course; and the information/term paper counseling model is apparent in the strong emerging relationship between the library and the Writing Center (WC).

\subsection{Institutional context}

Some institutional background is important in understanding the unique role of the Johnson Center Library as a "learning library." George Mason University began its history as a branch campus of the University of Virginia in 1957. In 1972, the General Assembly of Virginia passed legislation to establish Mason as an independent university in the Commonwealth's higher education system. Mason is a distributed university with campuses in the cities of Fairfax (the main campus) and Arlington, and in Prince William County. Total enrollment for Fall 1998 was 24,010, with 2110 being freshmen (George Mason University Factbook).

The mission of the George Mason University Libraries is to support the research needs of the university by educating students and faculty on how to find, evaluate, and use information of all kinds and in all formats. Following the liaison model of library service, all four libraries have an outreach network to students and faculty in academic departments. Subject specialists at Fenwick Library, the university's main research library, are responsible for providing research, instructional, and collection service to the major academic departments on the Fairfax campus. Johnson Center Librarians play a similar role by identifying programs with large student populations and actively participating in curriculum development, student orientation, assessment, and faculty training.

The Johnson Center Library is located within the Johnson Center, an academically focused "campus commons" designed to be an integrated learning environment. In addition to the library itself, the building contains computer labs, fast-food services, a theatre, a bank, a travel agency, a bookstore, a restaurant, and numerous academic program offices. Most striking is the collaborative, social atmosphere: there are many study rooms, group study tables, and other spaces for group study and discussion, with many network connections throughout the building allowing laptop computers to be used. The building is one model of how integrated, constructivist learning can happen through a network of interactions and associations in one physical space. The Johnson Center Library, as one significant part of the larger building, is one part of the "network" in the integrated learning environment. One of the most prominent linkages developed by the library is that with the NCC program.

\subsection{New Century College: course-integrated instruction}

$\mathrm{NCC}$ is a learning community. A learning community can be described as "a curricular structure that links together several existing courses so that students have opportunities for deeper understanding and integration of the material they are learning, and more interaction with one another and their teachers as fellow participants in the learning enterprise" (Gabelnick, MacGregor, Matthews, \& Leigh Smith, 1990). Valuing the premise that real-world problems are interdisciplinary, NCC is less interested in the rigid disciplines and more interested in solving the problems that connect them. The college offers "timely" programs that serve to connect interdisciplinary knowledge with real-world experience and lifelong learning skills by offering a 
plethora of active, hands-on learning experiences in which information literacy plays a key role.

Organizationally, NCC is a new paradigm at George Mason University. Students fulfill their general education requirements during an intensive first-year curriculum broken down into four highly collaborative, team-taught, interdisciplinary 6-week courses known as "units." After the first-year common curriculum, students are required to take upper level "learning communities" that combine subjects usually taught in separate classes into a single course of study. Students are also responsible for applying their knowledge by actively engaging in experiential learning activities, such as community service, overseas study, or internships.

Another goal of the curriculum is to immerse students in the NCC competencies of communication, critical thinking, problem solving, valuing, group interaction, global perspective, effective citizenship, aesthetic response, and information technology. In NCC, instead of "learning a discipline," students are asked to become competent in these broad areas that cut across subjects and are designed to be timeless and conceptual. In doing so, students are assessed on their ability to master these overlapping areas. Instead of traditional multiple-choice "recall" exams, the NCC curriculum requires students to make connections and apply their learning in multiple contexts from multiple perspectives. This is accomplished in many ways but mostly with intensive (and varied) research assignments, problem solving exercises, active use of information technology, and reflective and analytical portfolios that serve as final exams.

Throughout their experience, students closely interact with a campus-wide group of faculty, librarians, and graduate teaching assistants. Each faculty member brings to the classroom an expertise and unique way of knowing molded by his or her educational and professional background. Since each unit is integrated and covers many subjects, the emphasis is on making connections and the application of knowledge. That is, students have access to faculty members who are simultaneously experts and generalists. Some departments and programs from which faculty are drawn include English, Communication, Education, Conflict Resolution, and the library.

In an effort to integrate information literacy skills into the curriculum, the NCC liaison librarian "leaves the library" to team-teach in Unit I: NCLC 110, "Community of Learners." In Unit I, traditional courses like English 101, Communications 101, and Computer Science 106 are integrated so students are required to focus on relevant connections. The faculty group is responsible for creating a common syllabus, reading list, and assignments and projects for which each student is responsible. Each individual member of the team is responsible for a particular seminar, typically 20 students. Seminar instructors and students meet in seminar each morning to discuss the ideas, readings, and assignments of the course. Each afternoon students meet in a cluster-sized group to attend workshops taught by a member of the NCC faculty team or by an expert from outside the college. Information literacy concepts are integrated and reinforced by the seminar instructor who attends with the students. They do this by working on active, hands-on group assignments and projects that have multiple integration points - at the problem level (analytical reasoning, problem solving, and critical thinking), at the skill level (information technology, communication, conflict resolution), and at the content level (the particular assignment or task at hand). The description of the yearlong, integrated project is a good way to illustrate and develop this concept.

The NCC liaison librarian's role extends beyond Unit I. Coordinating a yearlong project A Transformation Story: One of Many - provides additional opportunities for strengthening the library's role in the NCC community. The Transformation Project is a cultural biography assignment designed to link the first year general education units and serves as a vehicle for 
students to develop a progression of research, writing, and technology skills. The project incorporates the NCC competencies and integrates each unit's main themes and ideas. The project consists of four chapters - one for each first-year unit - and a year-end analysis and reflective piece for a yearlong portfolio. Each student chooses a person to study for the year. In each unit, students research and write about their person in the context of the corresponding unit theme. In doing so, students are immersed in an environment in which information literacy concepts are a natural extension of their day-to-day coursework. The NCC liaison librarian, serving as yearlong manager of Transformation, plays a strong role in the design, implementation, and teaching of the project. Unlike faculty members, who rotate from unit-to-unit, the librarian is "involved" in each unit. Because librarians help to facilitate and provide unit-by-unit context and connection, students come to view them - and the library - as integral to the college experience.

Further evidence of participating in collaboration and promoting community is the libraries' relationship with the English Composition program, University 100, a course offered to assist students with the transition to college life, and the campus WC. Each of these programs has a particular niche to fill in the library's outreach to the campus, and each demonstrates specific programmatic/curricular elements showing what is possible in the learning library.

\subsection{English 101 (Freshmen Composition): course-related instruction}

The program at Mason with the largest student population is English 101, a required beginning composition course enrolling approximately 1800 to 2000 students each year. Because of the numbers of students, the libraries have historically relied on a library workbook that serves as an orientation vehicle and an introduction to basic research concepts. Completion of the workbook was a requirement for English 101. Students would answer questions posed throughout the workbook and turn them in to the library for grading. Graded answer sheets were then returned to the instructor. Because it was not associated with a specific writing assignment, and because it was graded by someone other than the instructor, students perceived it as busy work. Motivation to complete the workbook was low.

Over the past 2 years, the libraries have worked with the Composition program to develop a better way to integrate library instruction into the English 101 curriculum. The nearly 70 page workbook has been reduced to a 12-page guide. The George Mason University Libraries' Basic Guide to Research presents research concepts, emphasizing an electronic environment. Because of the continually changing nature of information access - database contracts expire and are not renewed, access software changes without warning, and Web pages with their accompanying links change overnight - students need a conceptual foundation for research. This approach fosters the underlying processes, mainly critical thinking and problem solving, that allow them to adapt to new situations.

But any library instruction, whether a workbook, guide, or handout, has little effect if it is not incorporated into the course. The liaison librarian to the Composition program has become more involved in helping instructors of English 101, many of whom are adjunct, incorporate the use of the guide into their class. The guide is most effective when the instructor presents it to the students as a resource from the library that will help them complete the assignment effectively. By linking the guide directly with writing assignments, course instructors and librarians alike believe that students will see research, and the library, as a more integral part of the writing process. Thus, the guide and the accompanying workshop are "course-related." While the guide is conceptual, the worksheet requires students to apply the research concepts in the context of the course so that 
students' research processes and writing processes become interrelated and integral to each other.

Currently under development for English 101 is a Web tutorial designed to teach the basic research concepts explained in the guide. This tutorial will also include quizzes to assess students' knowledge of those basic concepts. The Web tutorial and accompanying quizzes will become an important foundation for other components of the libraries' overall information literacy program. Longitudinal results from the quizzes should reveal gaps in student understanding of "the basics" and allow further refinement in the tutorial and in opportunities for more sustained interaction with students as they apply their developing knowledge throughout the course in a variety of assignments, and in other courses as well.

\subsection{University 100: orientation and peer advising}

University 100 is an elective, for-credit course offered each year to all new students to help them make the transition to college life and to George Mason University. The course, enrolling approximately 600 students, offers opportunities for students to develop skills necessary for a successful academic career. It also introduces students to the many resources available to them from both the academic and student life arenas of college. Specific objectives of University 100 are:

- $\quad$ assisting with academic, social, and cultural transition to college;

- developing a sense of community and school spirit;

- improving interpersonal relationships and appreciation of diversity;

- $\quad$ supporting academic and personal growth;

- $\quad$ enhancing critical thinking skills.

Making connections is a major theme of University 100. To this end, each section is taught by faculty and staff from many departments and offices on campus. In addition to the instructor each section has a peer advisor who is an upper-class student selected through an interview process. These peer advisors provide an important perspective on college life to University 100 students. This emphasis on making connections has allowed the libraries to become very involved in University 100, most notably with the preparation of the University 100 workbook and training of the peer advisors and instructors.

A required workbook covers each topic in the course (examples include Study Skills, Relationships, and Leadership Development). Instructors have the flexibility to present topics in whatever order they consider most appropriate for their class. The workbook contains exercises, assignments, and useful resources related to each topic. Beyond a self-guided tour of the Johnson Center Library offered in this workbook, each year the library provides a bibliography specific to each topic chapter that includes helpful resources, print and electronic, available in the university libraries. Because the bibliographies appear with each chapter, the students see a "library connection" with each topic. Because the bibliographies are presented as helpful resources and not as part of an unrelated assignment, the students may be more motivated to use the library. University 100 instructors and peer advisors are strongly encouraged to promote the use of the resources from the bibliographies throughout the course.

The niche that an orientation program can fill in the developing positive perceptions of the learning library is an important one. With University 100, the library is very involved in the required preparatory classes for both the peer advisors and instructors. The University 100 
program coordinators, instructors, and peer advisors strongly believe that, for many reasons, most incoming students are afraid to come to the library. Whether big or small, print or electronic, libraries are confusing, often uninviting environments. Students need to feel comfortable coming to the library and asking for help. Therefore, a major theme for the integration of the library into the University 100 program is "No Fear." Library staff members help the peer advisors to be a resource for using the library by training them to teach the basics of information access and conduct library tours. The goal is positive peer interaction in developing confidence in using the library and asking for assistance.

The library is also involved in the orientation required for all University 100 instructors. As with the peer advisors, the theme of "No Fear" is emphasized. Instructors are encouraged to promote the use of the topic bibliographies and given assistance incorporating them into their assignments, again reinforcing that the library is an integral part of the curriculum.

\subsection{Writing center: term paper counseling/advising}

Librarians in the Johnson Center have also progressed in developing a working relationship with the campus Writing Center. While discussing the importance of creating partnerships on campus at a university-sponsored workshop, the liaison librarian to the English Composition program and the Director of the WC quickly saw an opportunity to showcase both programs. Initially, jointly sponsored drop-in help sessions for both research and writing were offered in the Johnson Center. From simple beginnings, these help sessions have developed into a successful program that involves several staff from both the WC and the Johnson Center Library.

A Johnson Center Library graduate research assistant (GRA) coordinates these help sessions and is trained as a writing tutor. The library GRA now has scheduled time in the WC to help students. The benefits of this collaboration are numerous. Scheduling the GRA in the WC reinforces the idea that research is an integral part of the writing process. This also gives the WC staff a resource knowledgeable in library databases and other resources. Finally, this relationship ensures a liaison with the WC that, because the GRA position changes year to year, provides for new and innovative ideas for enhancing the partnership. The library GRA represents the effort to build community by integrating research and writing processes. This is also a goal for strengthening the relationship between the libraries and English Composition program.

\section{Conclusion: the web of influence}

Librarians in the Johnson Center Library have found that their very active involvement and outreach in promoting a learning library, both within the integrated Johnson Center environment and the larger campus setting, have created unforeseen opportunities for further influence in the university. They have been asked to teach full-time for parts of the NCC first-year curriculum, to assist with campus-wide assessment initiatives, to help with university reaccredidation studies, to serve on the writing-across-the-curriculum committee for the campus, and to become more involved in the university's technology-across-the-curriculum initiatives. The visibility for librarians is, of course, only an ancillary effect of the larger goal of creating a learning library, where partnerships, curricular integration, pervasive student-faculty-librarian interaction, and extended influence coalesce to form an integrated learning environment. This is the library as true constructivist space, whether physical, social, or virtual; as the place for conversation, coaching, and mentoring; as the network of associations made possible through in-person and electronic 
communication; and as the web of ideas and meanings that emerge in the minds of all who participate in it.

\section{References}

Gabelnick, F, MacGregor, J., Matthews, R. S., \& Leigh Smith, B. (1990). Learning communities: creating connections among students, faculty, and disciplines. New directions for teaching and learning no. 41 (p. 19). San Francisco: Jossey-Bass.

George Mason University Factbook. Available at: http://irr.gmu.edu/factbooks/9899/index.html.

Lave, J. (1991). Situated learning: legitimate peripheral participation. Cambridge, England: CambridgeUniv. Press.

Vygotsky, L. S. (1978). Mind in society: the development of higher psychological processes. Cambridge, MA: Harvard Univ. Press. 